\title{
SIMULAÇÃO DE UM MOTOR DE COMBUSTÃO FLEX
}

André Vinícius O. Maggio ${ }^{1}$, Marco Isola Naufal ${ }^{2}$, Marcos Henrique C. Silva ${ }^{1}$, Armando Antônio M. Laganá ${ }^{1}$, João Francisco J. Filho ${ }^{1}$, Angelo Maggio Neto ${ }^{1}$

${ }^{1}$ Escola Politécnica da Universidade de São Paulo (EP-USP)

${ }^{2}$ Instituto de Pesquisas Tecnológicas (IPT)

E-mails: andremaggio@usp.br, mnaufal@ipt.br, marcoshencarsil@gmail.com, armandolagana@terra.com.br, jjusto@1me.usp.br, angmaggio19@gmail.com

\section{RESUMO}

Nos últimos anos, a demanda por motores mais eficientes e com menores emissões vem crescido a níveis mundiais. O uso de biocombustíveis é uma alternativa mais limpa com relação ao uso de combustíveis fósseis, principalmente considerando suas emissões de carbono. O Brasil já faz uso do etanol em sua frota de veículos equipados com a tecnologia flex-fuel, porém projetar e otimizar um motor flex-fuel sempre gera novos desafios. Fazer o uso de simulações computacionais permite testar, validar e otimizar os algoritmos de controle da ECU (Engine Control Unit). Neste trabalho, é feita a modelagem de um motor flex-fuel e seus subsistemas de ar, térmico, mecânico e de combustível, tendo em vista suas características particulares com relação ao motor monocombustível. Os subsistemas serão interconectados, de forma a se obter o modelo global do motor, no hardware de simulação, e, posteriormente, implementada a integração de tal modelo de simulação com a Flex ECU.

\section{INTRODUÇÃO}

Com o avanço da tecnologia, ferramentais e instrumentais novos podem ser disponibilizados no ambiente acadêmico e na indústria. Desta forma, o aluno é enriquecido de diversas opções, dentre as quais não só ele poderá escolher a que melhor diminua a distância transacional, mas também a que forneça possibilidades técnicas que não houvera. Nesta última asserção, destaca-se a indisponibilidade de mídias através das quais determinados aprendizados se tornam desenleados. Será 
que há adequabilidade em prender o aluno, ou mesmo a indústria, a mídias tradicionais enquanto outras, modernas, se melhor enveredam na produtividade, na eficácia e na eficiência do aprendizado?

É insofismável o ganho da cátedra e da indústria, por exemplo, com a virtualização de plantas e laboratórios. Não mais a universidade e a indústria estão limitadas ao seu ambiente físico, às suas instalações físicas, pois correntemente podem dispor de plantas e laboratórios virtuais. O que impede as universidades federais e até de outras pátrias virtualizarem seus laboratórios e, em reciprocidade, ceder seu uso? O quanto ganharia o ensino, a ciência e a indústria se o aluno e o pesquisador tivessem, disponíveis, vários laboratórios mundiais no sistema de sua universidade ou empresa?

Com este cenário, e através deste artigo, vêm, os autores, expor a virtualização realizada de uma sala de ensaios do Laboratório de Motores do Instituto de Pesquisas Tecnológicas do Estado de São Paulo, sala na qual há dinamômetro de bancada, motor, sistema de coleta de dados, sistema independente de refrigeração do motor, tudo a ser melhor especificado na seção Resultados e Discussão.

Para a virtualização do motor, parte central da pesquisa desenvolvida, impelese a escolha de uma diretriz. Dependendo do objetivo escolhido, a modelagem a ser efetuada será distinta. O fenômeno é o mesmo, porém sua descrição, principalmente no que se refere ao estabelecimento das grandezas ditas de entrada e de saída, será diferente conforme a finalidade adotada. Uma expressiva vertente da modelagem se adentra nos projetos de design mecânico. Foca-se em deixar as grandezas geométricas como variáveis, não como constantes, de forma a otimizar o desenho do motor. Outra vertente, de não menor importância, objetiva o controle dos atuadores do motor. Nesta, as grandezas geométricas são constantes, não variáveis (excetuase quando o próprio desenho permite o controle da geometria através de atuadores, como no caso da taxa de compressão variável), de forma a otimizar a estratégia de gerenciamento do motor. 
Com a disponibilidade destes modelos virtuais, pode, a cátedra, oferecer meios ao discente para que este possa explorar vastamente a planta, mesmo havendo nesta universidade instalações físicas. Não há necessidade de reservar hora em laboratório, ou conferir a disponibilidade de horário deste, ou se preocupar com o tempo disponível. Não há preocupações relativas à segurança, ao custo de manutenção e operação das instalações, à possibilidade da presença de um docente a acompanhar as atividades, nem receio do aluno em danificar a instrumentação. Análogos comentários podem ser traçados à indústria.

Obviamente, há diferença entre a instalação física real, com o motor real em operação, e a instalação virtual, na qual se encontra o motor virtual programado. A experiência dos autores no Laboratório de Motores do IPT revelou-se fundamental em clarear aspectos indisponíveis no ambiente virtual, os quais apenas se poderiam vivenciar no ambiente real. Não que todos os aspectos não se pudessem jazer disponíveis. Entretanto, há limitação humana em apreender, mesmo com o uso da criatividade, todas as possibilidades que possam ocorrer dentro de um laboratório real, sendo que muitas ocorrências dentro deste têm sua causa, inclusive, desconhecida, não por causa da incapacidade técnica dos alunos ou pesquisadores, mas devido à irreprodutibilidade de várias ocorrências, o que tornaria a modelagem ou implementação destas irrazoáveis ao se considerar o método científico. Há ocorrências imprevisíveis (ou numa qualificação mais precisa: não previstas), entretanto, que podem ser reproduzidas, pois, devido à descoberta do binômio causa e efeito, conhece-se a relação física. Como exemplo, ao trocar um fio queimado e tornar o sistema operacional novamente, se infere com alto grau de razoabilidade que o fio queimado era a causa da não operabilidade.

Na modelagem desenvolvida pelos autores, não foram inclusos estes eventos, estas "falhas" no funcionamento do laboratório, de modo que o aluno não será surpreendido por componentes que queimam, por interrupções indesejadas do líquido refrigerador ou da água do dinamômetro hidráulico, por vazamentos no sistema laboratorial de exaustão, por falta de lubrificação no eixo do dinamômetro. Tudo funcionará dentro da idealidade. O aprendizado do aluno estará circunscrito, portanto, àquilo que fora objetivado pela modelagem, qual seja, o comportamento dos 
atuadores ou o impacto de diferentes geometrias. Eis uma das principais diferenças técnicas entre o laboratório virtual criado e o laboratório real. Cite-se outra: não foi empregado, no laboratório virtual, a variância dos dados, de forma que, para um determinado conjunto de entrada, haverá sempre a mesma saída.

Finalmente, impera-se dizer a escolha adotada. O modelo desenvolvido e trazido aqui à apreciação dos leitores refere-se ao comportamento dos atuadores. Como o cerne desta modelagem é o desenvolvimento de estratégias de controle e gerenciamento, as quais são projetadas baseadas nos dados dos sensores, deve-se modelar os sinais destes. São estes sinais, agora virtuais, modelados, que serão a saída da planta virtual, sinais estes que alimentarão a unidade central de controle do motor (engine $E C U$ ). Logo, o aluno e o pesquisador poderão não só explorar a planta, como também explorar estratégias de controle.

O artigo em questão tem vistas a elencar e expor as principais funcionalidades do laboratório virtual, sumarizando ensaios sugeridos que em nada têm por finalidade limitar a criatividade do docente ou do aluno, que poderão desenvolver ensaios inclusive não vislumbrados pelos autores. Do contrário, deseja-se simplesmente, com as simulações aqui realizadas, proporcionar ao leitor um melhor insight do sistema.

Conforme consta no resumo, são estes os subsistemas, cuja integração concebe o sistema global: subsistema de ar, subsistema de combustível, subsistema térmico e subsistema mecânico. Destaca-se que tal não fora realizado para um motor flex-fuel (se o fora, permaneceu em segredo industrial). Com isto, pretende-se agregar maior valor ao trabalho realizado, avançando na simulação de motores através de uma implementação na qual agora há uma importante grandeza a mais: o uso de bicombustível.

\section{METODOLOGIA}

Inicialmente, fora realizado um estudo dos modelos desenvolvidos pelo Instituto Federal de Tecnologia de Zurique (ETH Zurich), de forma a não só entender os 
modelos monocombustíveis desenvolvidos por este instituto, como também ampliálos ao panorama flex-fuel. Adotou-se a metodologia bottom-up, começando pelos estudos dos subsistemas para se culminar no sistema global. Em [1], [2], [3] e [4], encontram-se reproduzidos os estudos dos subsistemas, respectivamente, de ar, de combustível, mecânico e térmico.

O subsistema de ar é responsável por predizer valor médio do fluxo de ar admitido, como que sendo uma virtualização do sensor MAF (porém, apenas para valores médios), e o sinal do sensor de pressão no coletor de admissão (MAP) (mesmo em condições transientes), o qual estará também virtualizado no hardware de simulação. O valor médio do fluxo de ar é de interesse para o subsistema de combustível e o sinal da pressão no coletor de admissão é de interesse a todos os subsistemas, havendo realimentação também no próprio subsistema de ar.

O subsistema de combustível informa o fluxo médio de combustível admitido pelo cilindro, necessário para estabelecer, conjuntamente com o fluxo médio de ar, a relação equivalente ar/combustível. Conjuntamente com o subsistema de combustível, emprega-se a modelagem dos percursos da mistura ar-combustível, para conhecer a resposta do sinal lambda em função do tempo (que engloba, além da vaporização, as dinâmicas no sistema de exaustão). Este sinal alimenta todos os subsistemas que dependem da relação lambda, a saber: o mecânico e o térmico. No mecânico, a relação lambda influi fortemente na eficiência de combustão e no térmico, conjuntamente com a massa de combustível admitida, é necessária para conhecer os fluxos de entalpia tanto no duto de entrada quanto no de saída do cilindro. No subsistema de combustível, portanto, virtualiza-se o sensor lambda.

A modelagem do subsistema mecânico pode ter, por finalidade, criar um sensor virtual de torque. Recebendo, conforme argumentado, o sinal lambda, assim como o fluxo médio de combustível admitido, de forma a se conhecer a energia química admitida, conjuntamente com o ângulo de ignição, a rotação do motor, a pressão no coletor de admissão e a temperatura do motor, concebe-se um valor modelado de torque. O ângulo de ignição é mera entrada (todo sinal de atuador é entrada no sistema global). A rotação do motor pode ser tanto escolha do aluno quanto saída de 
um bloco. Ao adotar como escolha, está-se, mais fielmente, reproduzindo o ambiente do laboratório, no qual, comumente, escolhe-se de início uma rotação, a qual será mantida pelo dinamômetro. Entretanto, existe a opção de, conhecida a inércia do motor, e inserindo uma carga de torque (load torque), deixar a rotação do motor como variável.

O subsistema térmico objetiva virtualizar o sensor de temperatura do motor. Para isto, conforme parcialmente já mencionado, deve-se conhecer os fluxos de entalpia nos dutos de entrada e de saída dos cilindros, os quais são quantificados através do fluxo médio de combustível conjuntamente com a relação equivalente ar/combustível e com a rotação do motor. As perdas energéticas por fricção e bombeamento gasoso são informados pelo modelo mecânico. A temperatura dos gases de escape é modelada em função da pressão no coletor de admissão e da rotação do motor, ambos cuja obtenção já fora explicada.

Com toda esta modelagem, uma série de outros sensores virtuais estarão disponíveis, mesmo que não haja um respectivo físico real no motor de fato. Pode-se virtualizar várias grandezas, como pressão no coletor de escape, temperatura dos gases no coletor de escape, temperatura da água entrando no motor, temperatura do óleo, torque (conforme já mencionado), relação lambda após a válvula de escape ou em qualquer outro local de interesse. Com isto, pode-se implementar estes sensores virtuais na própria ECU, o que possibilitaria o uso de novas estratégias de controle. Pode-se, inclusive, eliminar alguns sensores físicos, visando economicidade, e usar apenas o virtual na ECU.

O leitor interessado poderá obter maiores informações técnicas sobre a modelagem do subsistema de ar em [5], [6] e [7], sobre a modelagem do subsistema de combustível em [5], [8] e [9], sobre a modelagem do subsistema mecânico em [5] e [6] e sobre a modelagem do subsistema térmico em [5] e [10].

Por fim, salienta-se que, conforme [11], usou-se a escala $\mathrm{HX}$, sendo $\mathrm{HO}$ a gasolina tipo C (E27) e H100 o etanol hidratado (E95h). 


\section{RESULTADOS E DISCUSSÃO}

O objetivo desta seção será expor tanto a validação deste laboratório virtual enquanto, conjuntamente, demonstrar experimentos que podem ser realizados pelos alunos. Os alunos poderão explorar a admissão de ar, analisando grandezas que envolvem todo o sistema de admissão nos seus mais diversos compartimentos, como na válvula borboleta, no coletor de admissão e no próprio cilindro, considerado na modelagem do subsistema de ar como uma bomba de ar. Poderão explorar a vaporização do combustível, as turbulências e seus efeitos sobre o fluxo no sistema de exaustão, a produção de torque (geração de energia mecânica) e o aquecimento do motor.

O laboratório físico real utilizado pelos autores para a virtualização pode ser visto na figura 1.

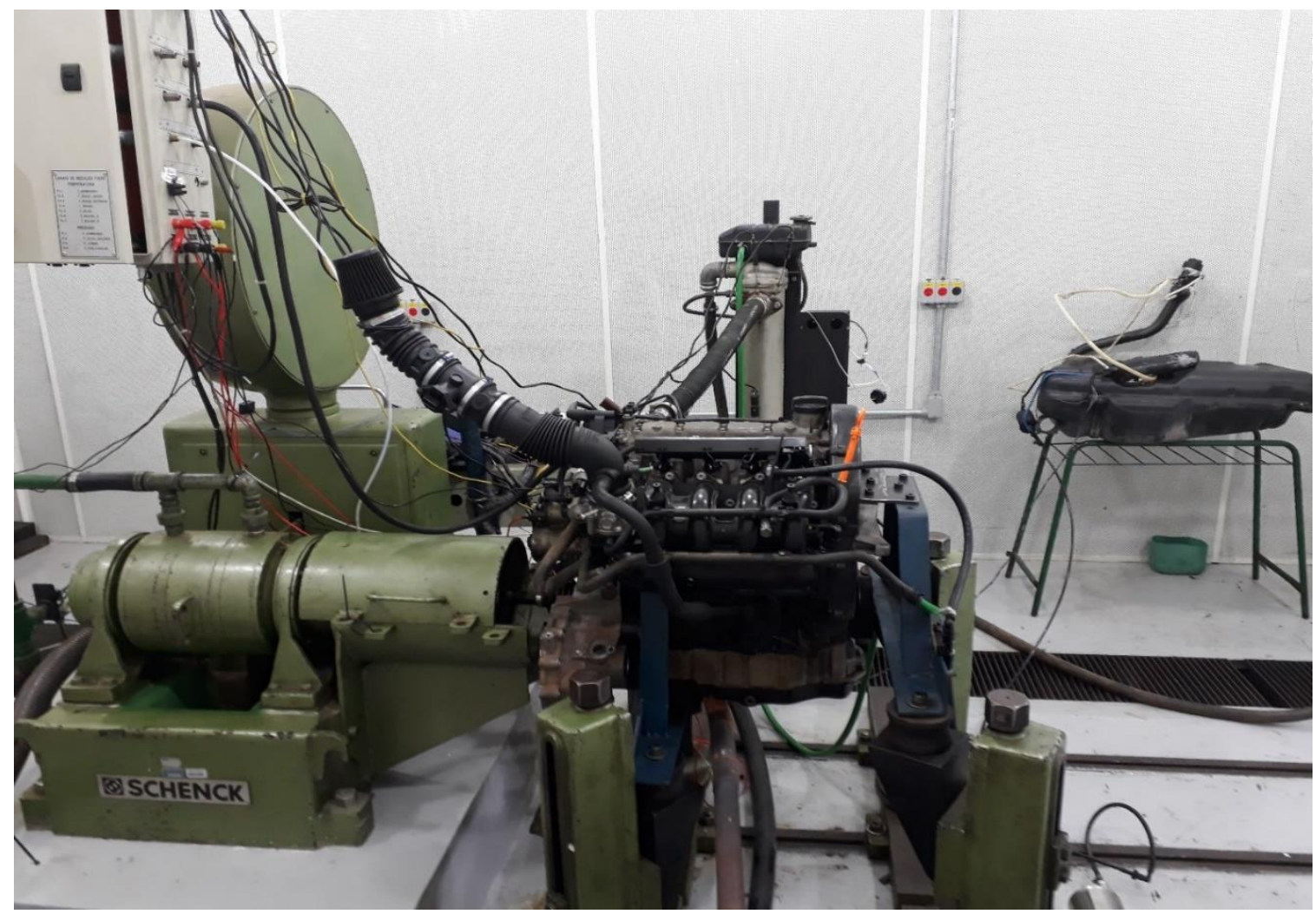

Figura 1: Motor na sala de ensaios do IPT. Vide-se o tanque de combustível, o sistema independente de refrigeração, o dinamômetro hidráulico e o motor EA 111 VHT 1.6L utilizado. 
A implementação dos dados referentes à figura 2 objetiva fornecer ao aluno, através de experimentos acadêmicos que podem ser desenvolvidos com esse intuito, a relação dentre o tempo de injeção (ou mesmo o sinal de atuação no bico injetor) com a vazão volumétrica de combustível injetada.

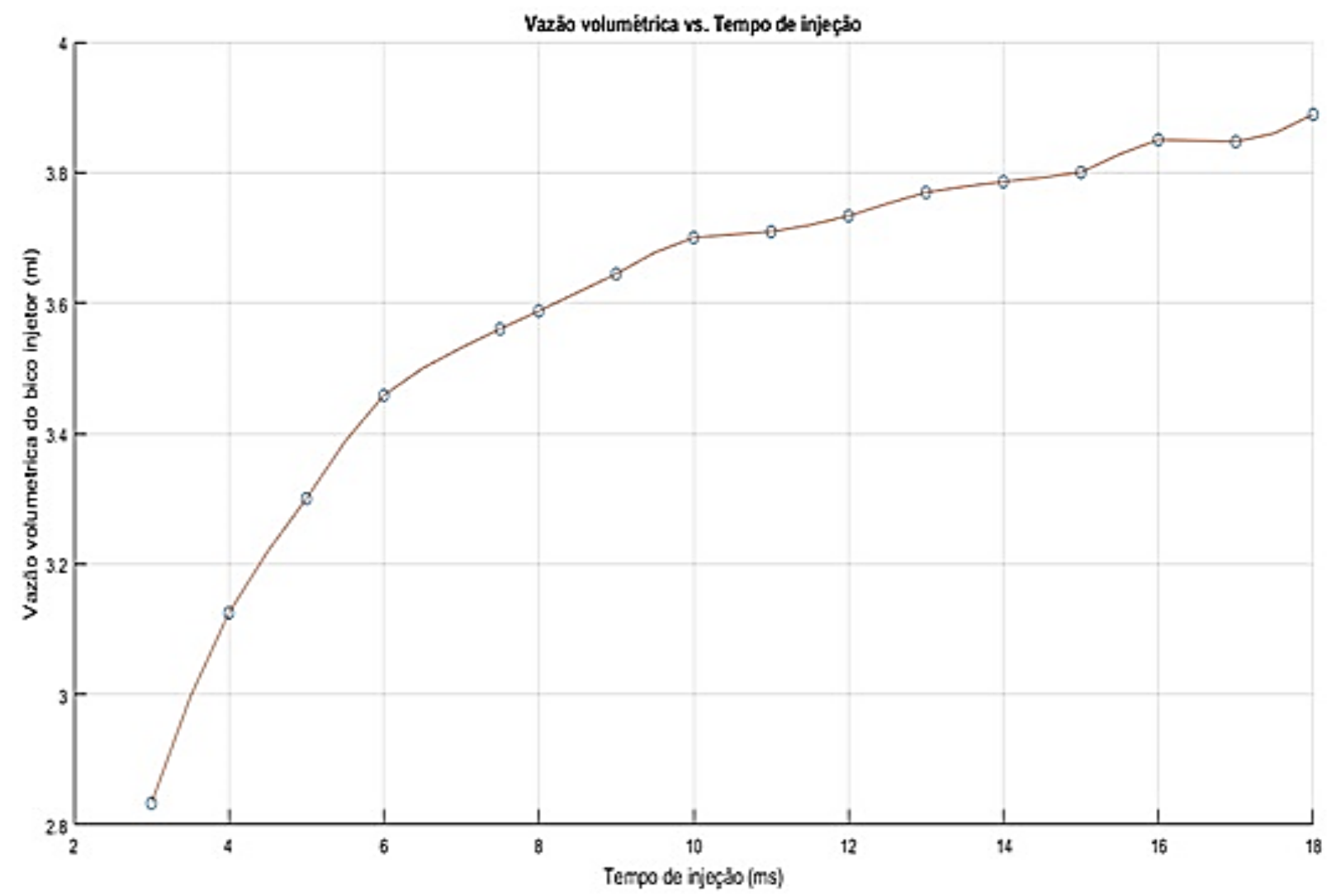

Figura 2: Vazão volumétrica do bico injetor. Observe a inconstância da relação entre o tempo de injeção e a vazão volumétrica.

A figura 3 mostra o mapa da função característica da válvula, com sua validação exposta na tabela 1. Com estes dados, o aluno pode estudar de forma isolada a vazão volumétrica através da válvula borboleta, tanto com rotação do motor constante, ou ângulo de abertura constante, ou mesmo os dois variando. Devido a válvula borboleta ser o atuador de controle do fluxo de ar, pode, o aluno, usando este mapa, elaborar estratégias de controle que direcionam a válvula na posição exata, para uma dada rotação do motor, de forma a se obter o fluxo desejado. 


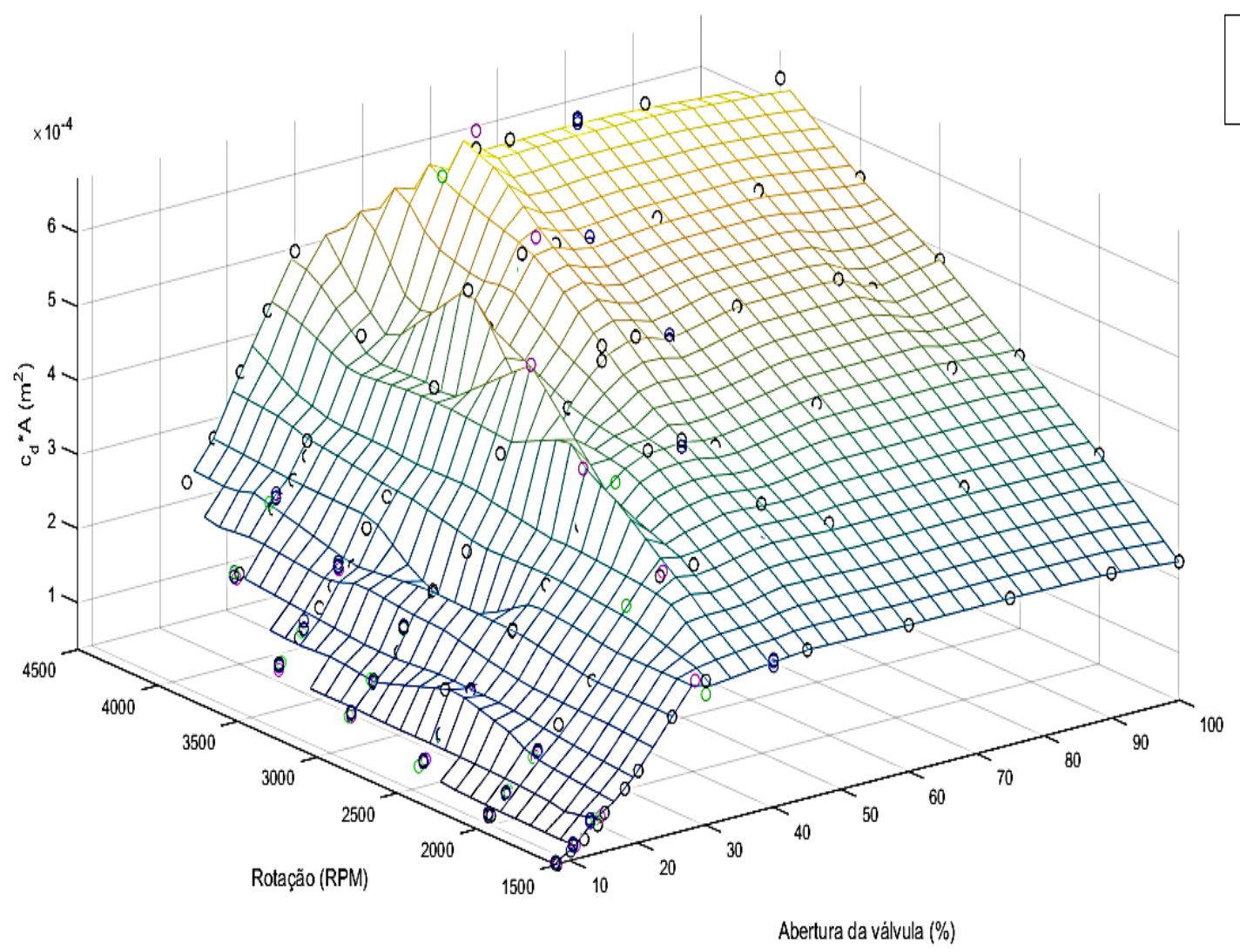

Figura 3: Função característica da válvula (produto da área de abertura da válvula pelo coeficiente de descarga desta). De forma a se usar a modelagem isentrópica no fluxo da válvula, usa-se coeficiente de descarga variável [12]. Observe a saturação no fluxo, para uma mesma rotação do motor, a partir de uma determinada abertura da válvula.

\begin{tabular}{c|c}
\hline Pontos testados & 45 \\
\hline Erros acima de $10 \%$ & 4 \\
\hline Erros acima de $15 \%$ & 3 \\
\hline Erro médio & $4,28 \%$ \\
\hline Mediana do erro & $2,89 \%$ \\
\hline Desvio padrão do erro & $5,19 \%$ \\
\hline Erro máximo & $27,39 \%$ \\
\hline
\end{tabular}

Tabela 1: Estatísticas do erro para a função característica da válvula borboleta. Usaram-se como dados de identificação os obtidos com as composições H0, H53, H56 e H100. Para validação, usaram-se os dados obtidos com as composições H34 e H71. 
$\mathrm{Na}$ figura 4, reproduz-se a eficiência volumétrica, seguindo-se a tabela 2, que mostra sua validação. A eficiência volumétrica interfere no fluxo de ar admitido, pois, ao influenciar o fluxo médio através do cilindro, correlaciona-se com a pressão no coletor de admissão, influindo, portanto, no próprio fluxo através da válvula borboleta. Com este mapa, o aluno poderá explorar a aspiração da mistura de ar-combustível pelo cilindro. Poderá constatar, dentro outros aspectos, que o simples aumento na magnitude na pressão do coletor de admissão não acarreta necessariamente em aumento de fluxo, mesmo para uma rotação constante do motor.

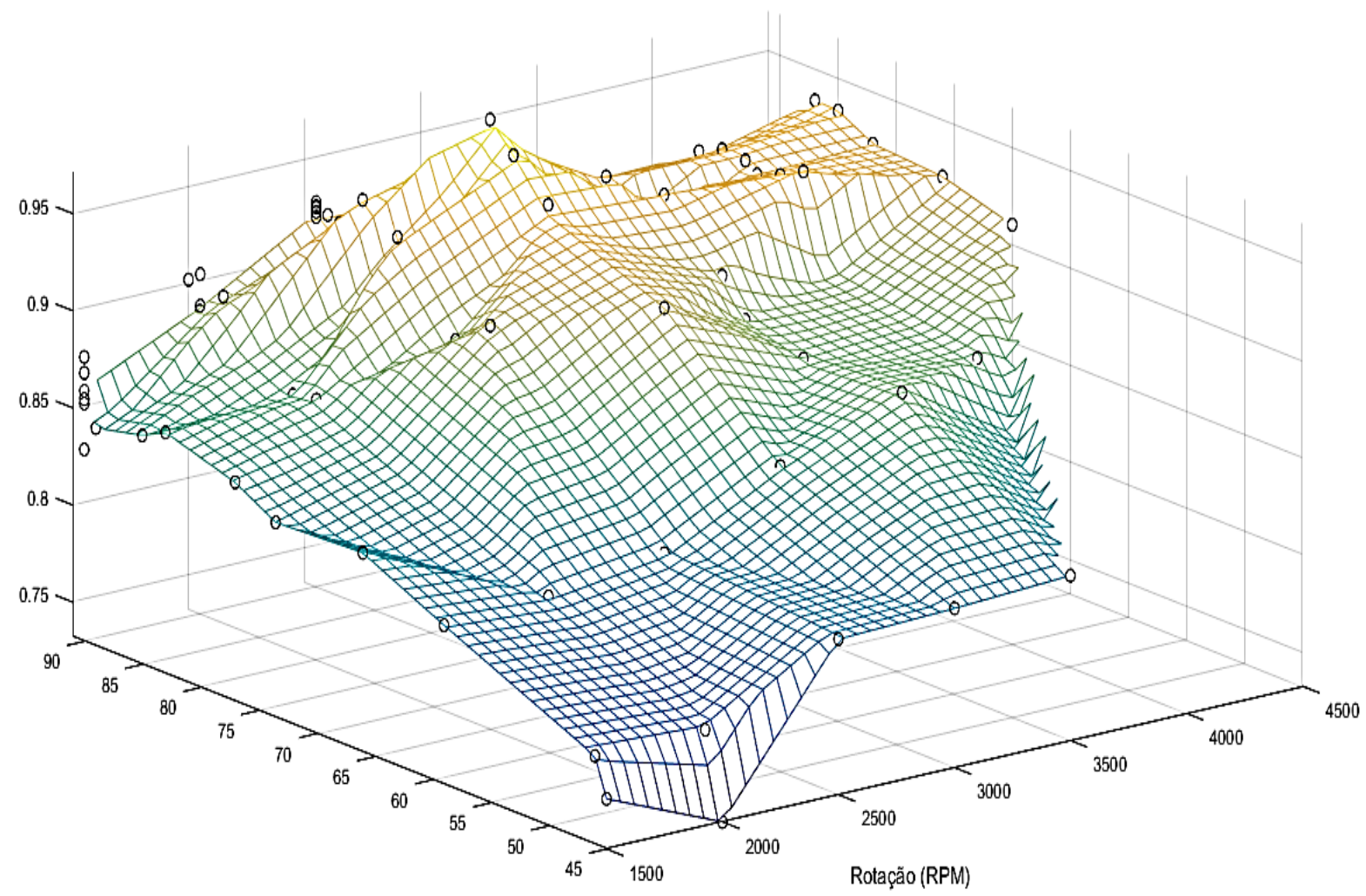

Pressão no coletor de admissão $(\mathrm{kPa})$

Figura 4: Eficiência volumétrica para H0. Foram levantados mapas da eficiência volumétrica também para as composições H56 e H100, como pode ser consultado em [13]. 


\begin{tabular}{c|c}
\hline Pontos testados & 69 \\
\hline Erros acima de 10\% & 0 \\
\hline Erros acima de 15\% & 0 \\
\hline Erro médio & $2,85 \%$ \\
\hline Mediana do erro & $2,28 \%$ \\
\hline Desvio padrão do erro & $2,46 \%$ \\
\hline Erro máximo & $8,90 \%$ \\
\hline
\end{tabular}

Tabela 2: Estatísticas do erro para a eficiência volumétrica. Foram coletados dados para as composições H0, H56 e H100 para serem usados como dados de identificação. Para a validação, colheram-se dados usando-se H34, H53 e H71.

Na figura 5 e na figura 6, reproduz-se o sinal no tempo, tanto modelado como medido, da pressão no coletor de admissão. Observe a primeira perda na aprendizagem do aluno, devido ao sinal simulado não ter as variações bruscas do sinal real, aparentando-se como que, mesmo não o sendo, uma versão filtrada do sinal real. O aluno perderá esta experiência de visualizar as mudanças bruscas do sinal azul causadas pela abertura e fechamento da válvula de admissão. Porém, o sinal vermelho é suficiente para a visualização de conceitos mais genéricos e para o uso em projeto de estratégias de controle. 


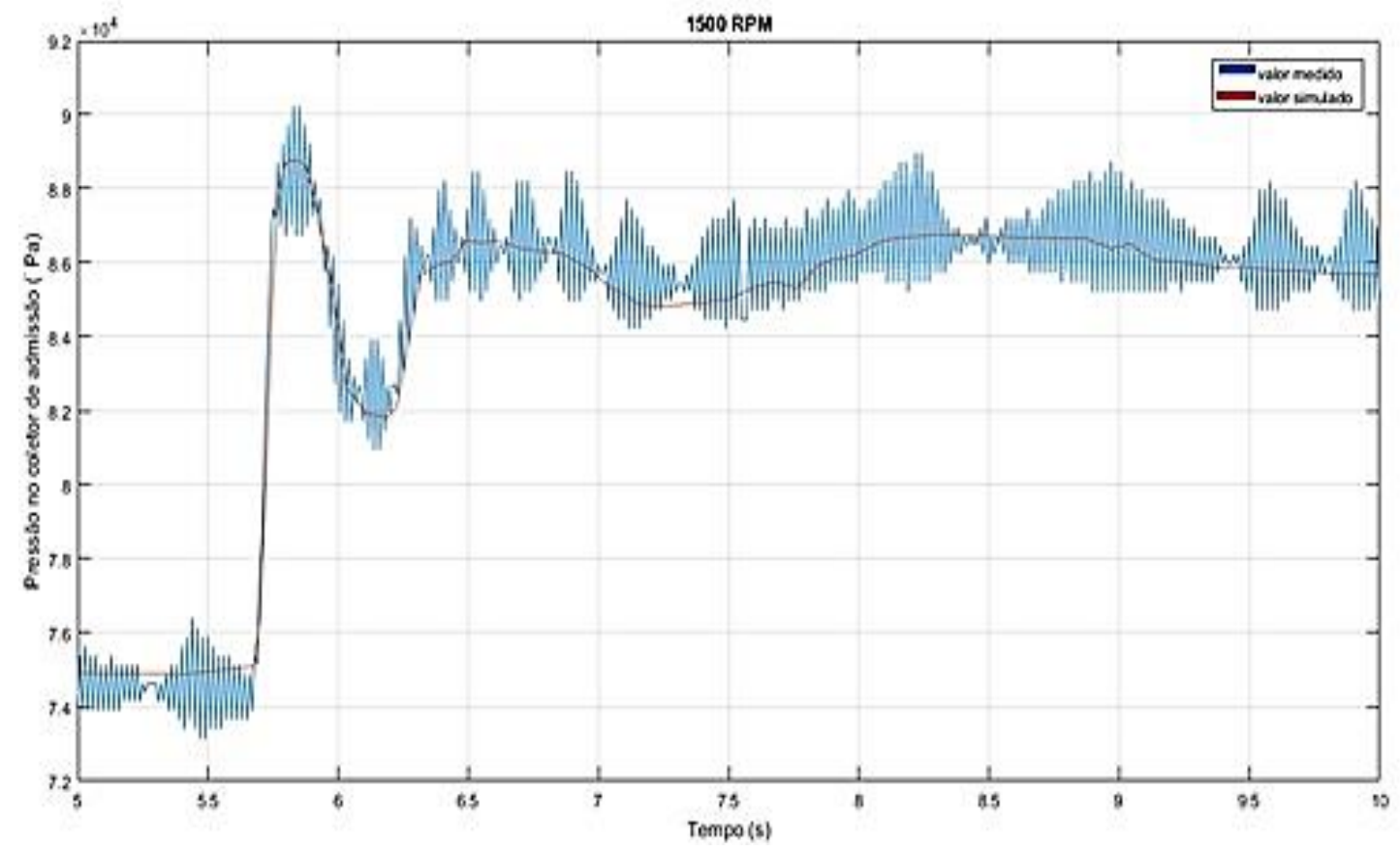

Figura 5: Sinal medido (azul) e simulado (vermelho) da pressão no coletor de admissão para HO. Realizou-se degrau na borboleta para obter a variação brusca no sinal. Ensaio realizado a 1500 RPM. Degrau gerado pela Flex ECU.

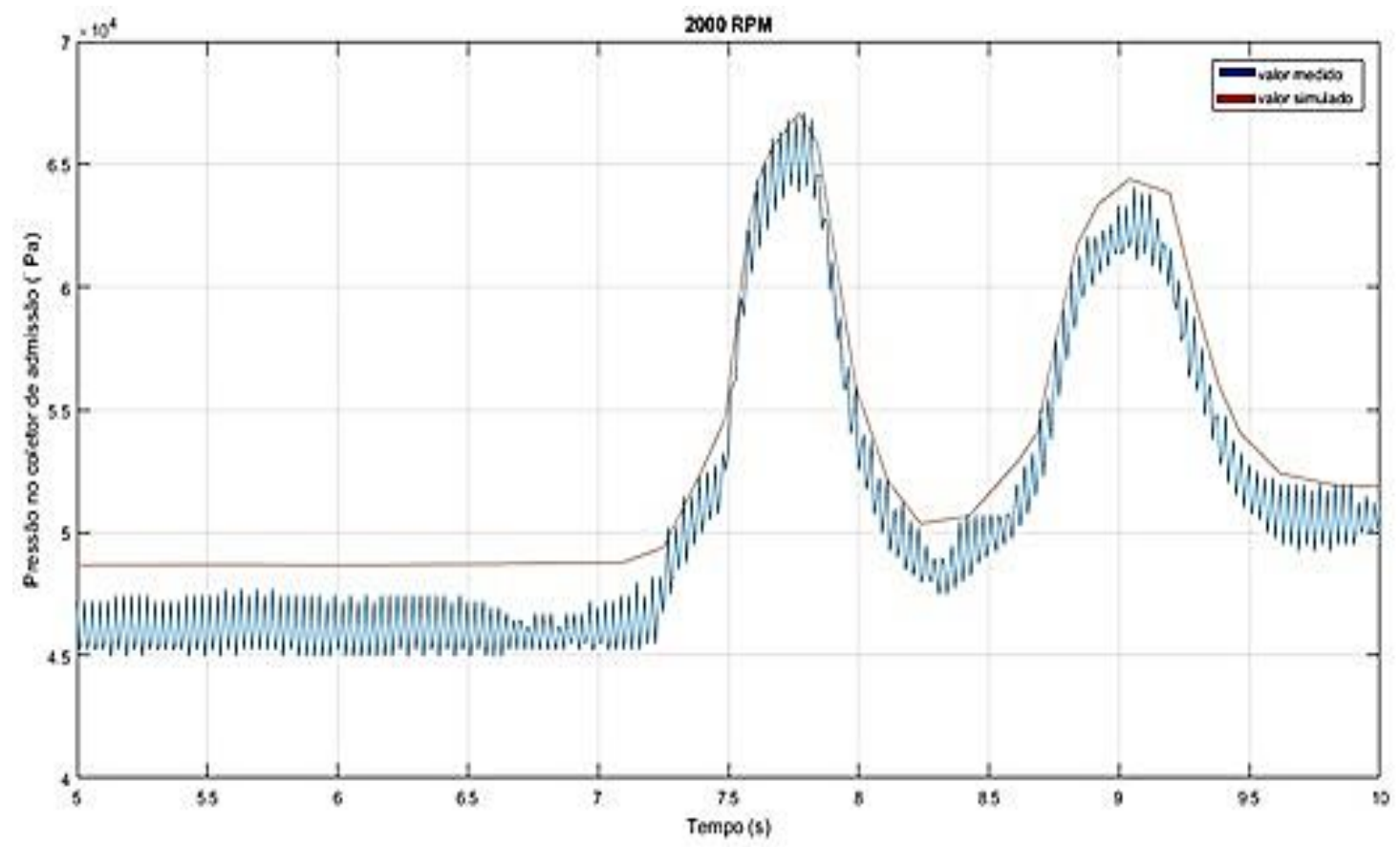

Figura 6: Sinal medido (azul) e simulado (vermelho) da pressão no coletor de admissão para H0. Operou-se o motor em uma condição instável e obtiveram-se os resultados expostos. Ensaio realizado a 2000RPM. Degrau gerado pela Flex ECU. 
Na tabela 3, encontram-se as métricas estatísticas referentes à comparação entre o valor médio de torque efetivo medido e modelado. De todo o trabalho, foi onde se obteve o maior erro devido à própria inconstância e variabilidade da combustão. Na propagação da chama, no ambiente de um motor de combustão interna, sempre haverá algo de caótico. Observe que, dado o erro médio e o desvio padrão, pode-se emular para o aluno esta variabilidade.

\begin{tabular}{|c|c|}
\hline Pontos testados & 214 \\
\hline Erros acima de $10 \%$ & 49 \\
\hline Erros acima de $15 \%$ & 19 \\
\hline Erros acima de $20 \%$ & 6 \\
\hline Erro médio & $6,30 \%$ \\
\hline Mediana do erro & $4,39 \%$ \\
\hline Desvio padrão do erro & $6,04 \%$ \\
\hline Erro máximo & $34,24 \%$ \\
\hline
\end{tabular}

Tabela 3: Estatísticas do erro para o modelo do torque. Para a identificação, usaram-se dados referentes a ensaios realizados com H0, H22, H47, H59 e H100. Para a validação, usaram-se $\mathrm{H} 37$, $\mathrm{H} 53$ e $\mathrm{H} 71$.

Na figura 7 e na figura 8 , mostram-se as curvas modelada e medida do sinal do sensor lambda pré-catalítico dado um degrau no bico injetor. Observe, novamente, a tendência da curva modelada ser mais suave, configurando uma perda de aprendizado para o aluno. A modelagem, no entanto, é suficiente para o ensino de noções gerais, assim como experimentos acadêmicos e até industriais relacionados a estratégias de controle. $O$ aluno também tem disponível um sensor lambda virtual após a válvula de escape, podendo, portanto, comparando o sinal deste com o précatalítico, analisar a influência isolada do sistema de exaustão. 


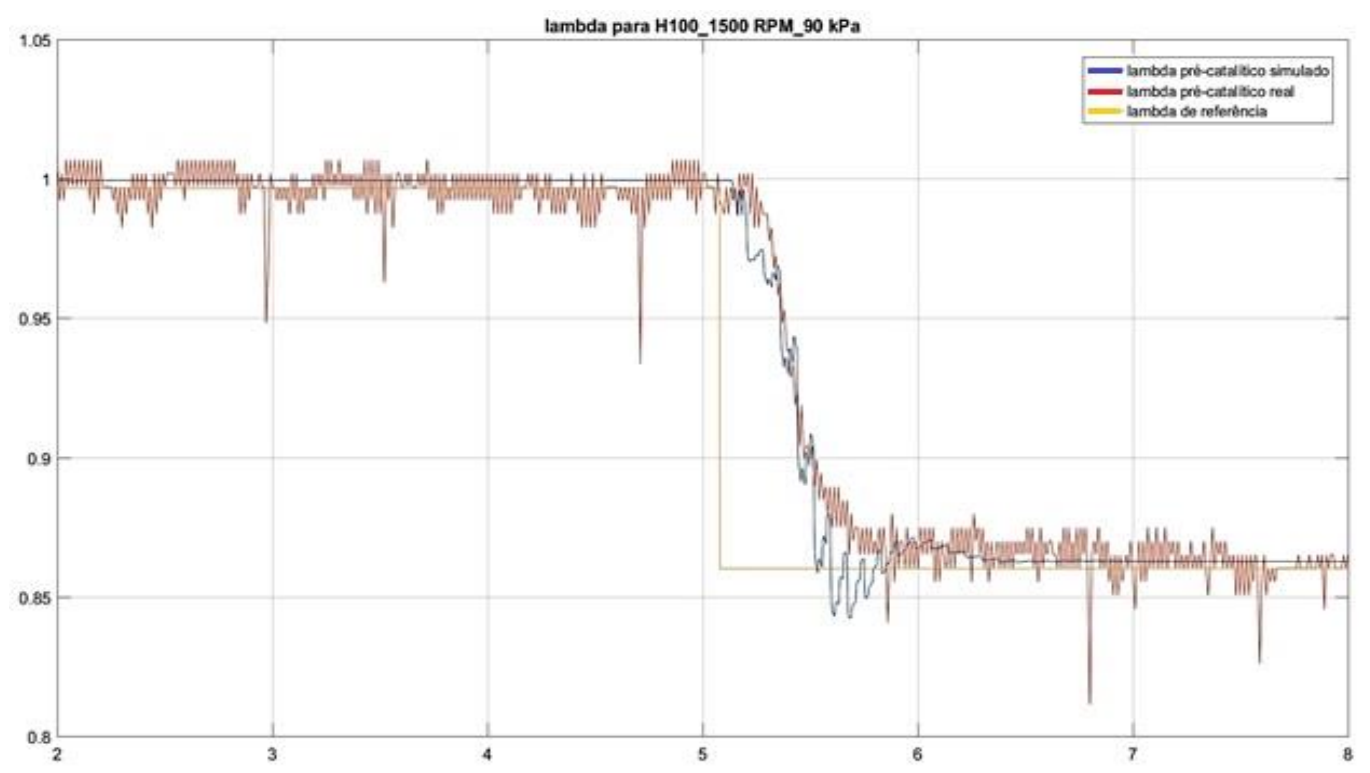

Figura 7: Sinais para $\mathrm{H} 100,1500 R P M$ e $90 \mathrm{kPa}$ em função do tempo em $s$. Observe o sinal lambda pré-catalítico simulado (azul), o sinal lambda pré-catalítico medido (vermelho) e o sinal lambda de referência (amarelo). Entende-se por sinal lambda de referência a relação equivalente ar-combustível da mistura admitida (vide [7]). Aplicou-se degrau no bico injetor para a mudança brusca no sinal do sensor lambda pré-catalítico. Ensaios para outras condições e composições podem ser consultados em [13]. Degrau gerado pela Flex ECU.

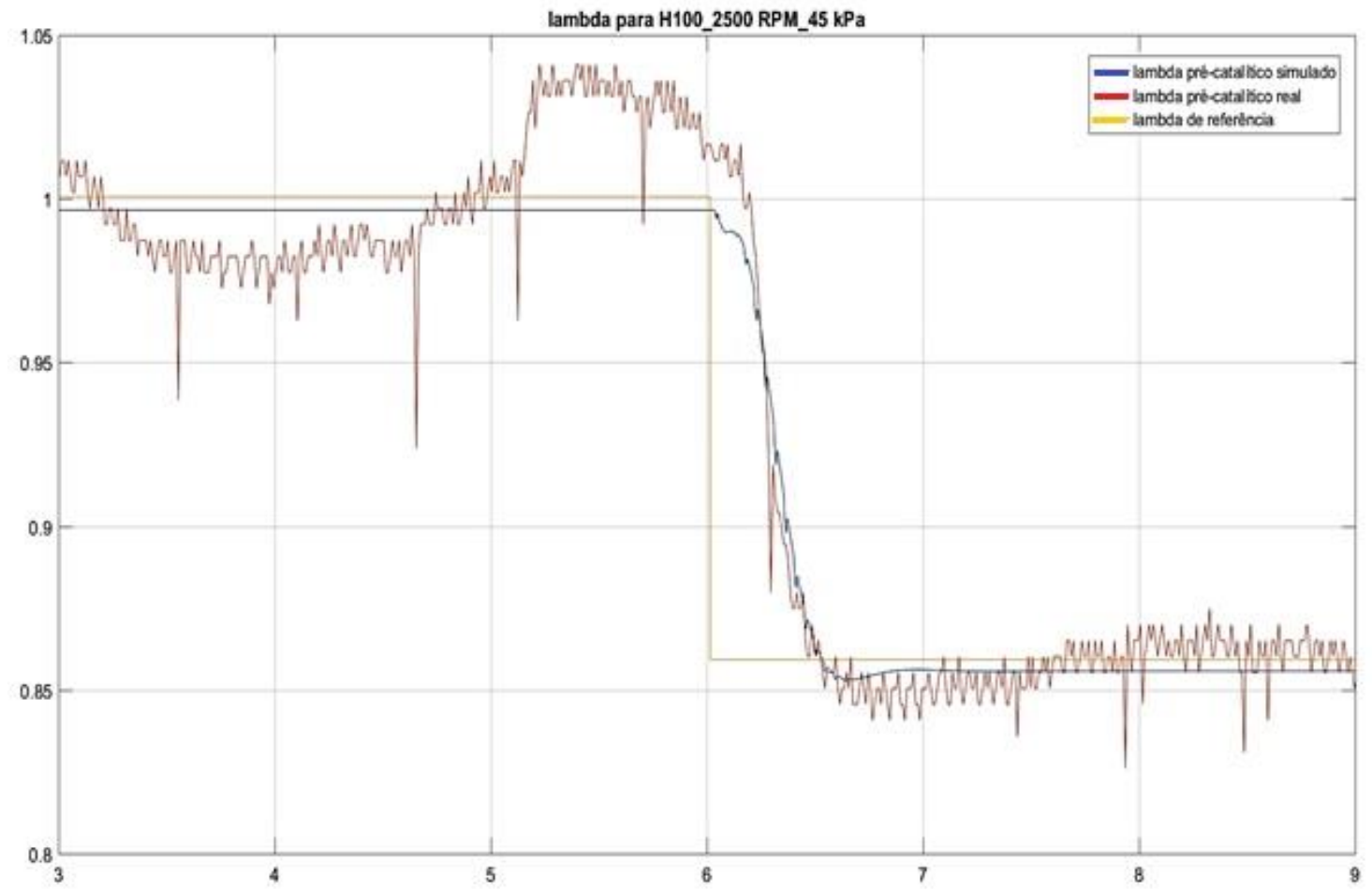


Figura 8: Sinais para H100, 2500RPM e 45kPa em função do tempo em $s$. Observe o sinal lambda pré-catalítico simulado (azul), o sinal lambda pré-catalítico medido (vermelho) e o sinal lambda de referência (amarelo). Degrau gerado pela Flex ECU.

A figura 9 emula o sinal do sensor da temperatura do motor, que mede a temperatura do líquido refrigerador saindo do motor. Mostram-se os sinais medido e simulado. A implementação da modelagem do sistema térmico no hardware de simulação é importante devido à influência que a temperatura do motor exerce em diversos aspectos. No sistema global, o sistema térmico, apesar de receber várias grandezas do sistema mecânico conforme discutido, realimenta o próprio sistema mecânico com a temperatura do motor, devido a esta ter forte influência na perda relacionada à fricção das partes mecânicas.

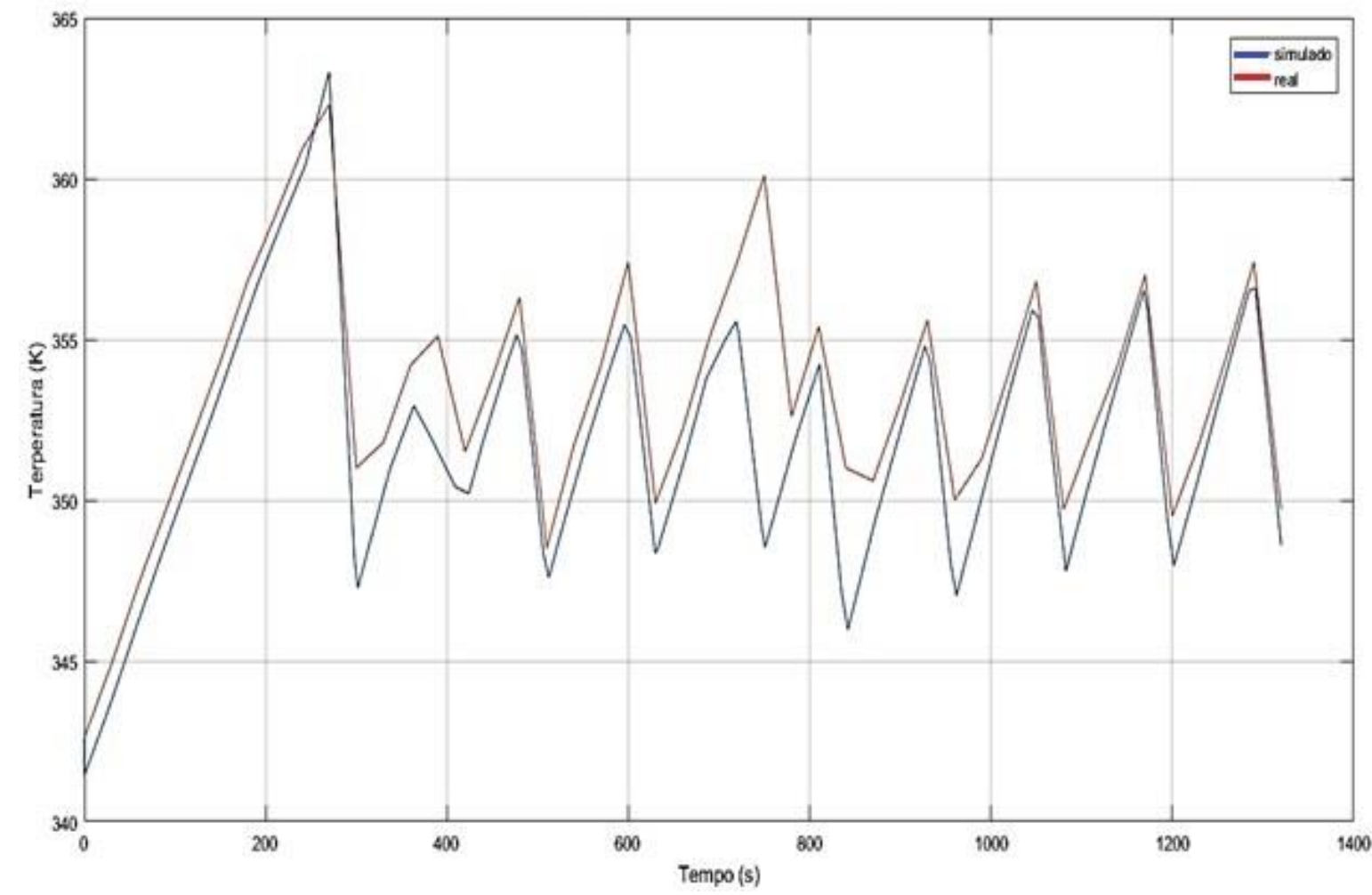

Figura 9:Temperatura do líquido arrefecedor saindo do motor para H0. Sinal simulado (azul) reproduzido conjuntamente com o sinal medido (vermelho). Durante o ensaio, variaram-se a pressão no coletor de admisssão, a rotação e o ângulo de ignição. Relação equivalente arcombustível mantida constante em 1. 


\section{CONCLUSÃO}

Neste artigo, procurou-se proporcionar ao leitor uma visão sobre as possibilidades acadêmicas e, acessoriamente, industriais, que a modelagem realizada proporciona, através da simulação de um motor flex-fuel a combustão interna: o motor EA 111 VHT 1.6L.

Devido a modelagem, em software, ser unicamente programada através de Matlab script e Simulink, pode o aluno fazer simulações em seu próprio notebook. Porém, caso seja necessário o uso de resposta em tempo real, mormente para testes voltados à comunicação com a ECU, visando o conhecimento da estratégia de controle do fabricante ou mesmo projetos autorais de gerenciamento, é mister o uso de um hardware de simulação adequado, de forma a viabilizar a consecução do hardware-in-the-loop. Neste caso, a universidade ou a indústria deverá dispor de um hardware de simulação adequado para resposta em tempo real.

Com isso, os autores julgam que seu trabalho possa ser usado tanto por alunos que cursam matérias introdutórias ao motor de combustão interna, quanto aquelas voltadas para a eletrônica embarcada automotiva, ou mesmo para matérias quaisquer de controle ou sinais.

Existem trabalhos sendo desenvolvidos na Escola Politécnica de forma a aprimorar a modelagem exposta. Em [14], objetiva-se modelar toda a interface (sensores e atuadores) de forma que a entrada e a saída do sistema global sejam sinais meramente elétricos (tensão constante, PWM), assim como testar o sistema global em condições ainda não testadas. Em [15], está-se desenvolvendo o incremento para abrigar uma variável a mais: o volume da câmara de combustão, o que se concretizaria no implemento da taxa de compressão variável. Para isto, vários testes com taxas estatísticas distintas já foram realizados e o impacto da taxa variável nos diversos sistemas será acrescentado, enriquecendo a experiência do aluno.

\section{REFERÊNCIAS}

[1] SILVA, Marcos Henrique C.; LAGANÁ, Armando Antônio M.; "MODELAGEM DOS SISTEMAS DE ADMISSÃO DE AR PARA MOTORES COM TECNOLOGIA FLEX", p. 
724-736. In: SIMEA. São Paulo: Blucher, 2017. ISSN 2357-7592, DOI 10.5151/engpro-simea2017-54

[2] SILVA, Marcos Henrique C.; LAGANÁ, Armando Antônio M.; "MODELAGEM DOS PERCURSOS DA MISTURA AR/COMBUSTIVEL PARA UM MOTOR COM TECNOLOGIA FLEX", p. 345-357. In: SIMEA. São Paulo: Blucher, 2017. ISSN 23577592, DOI 10.5151/engpro-simea2017-26

[3] SILVA, Marcos Henrique C.; LAGANÁ, Armando Antônio M.; "MODELAGEM DE TORQUE PARA MOTORES COM TECNOLOGIA FLEX", p. 767-779. In: SIMEA. São Paulo: Blucher, 2017. ISSN 2357-7592, DOI 10.5151/engpro-simea2017-57

[4] MAGGIO, André Vinicius Oliveira; SILVA, Marcos Henrique Carvalho; LAGANÁ, Armando Antônio M.; JUSTO FILHO, Joao Francisco; "MODELAGEM DOS SISTEMAS TÉRMICOS PARA MOTORES COM TECNOLOGIA FLEX", p. 625-639. In: SIMEA. São Paulo: Blucher, 2017. ISSN 2357-7592, DOI 10.5151/engpro-simea201748

[5] GUZZELLA, Lino; ONDER, Christopher. Introduction to modeling and control of internal combustion engine systems. Springer Science \& Business Media, 2009.

[6] MOSKWA, John Joseph. Automotive engine modeling for real time control. 1988. Tese de Doutorado. Massachusetts Institute of Technology.

[7] ERIKSSON, Lars; NIELSEN, Lars. Modeling and control of engines and drivelines. John Wiley \& Sons, 2014.

[8] SIMONS, Michael Richard. Modellbildung und Parameteridentifikation für die Wandfilmdynamik eines Otto-Motors. 2001. Tese de Doutorado. ETH Zurich.

[9] LOCATELLI, Marzio A. Modeling and Compensation of the Fuel Path Dynamics of a Spark Ignited Engine. 2004. Tese de Doutorado. ETH Zurich. 
[10] KANNE, Elena Cortona. Engine thermomanagement for fuel consumption reduction. 2000. Tese de Doutorado. ETH Zurich.

[11] MELO, T. C. Análise experimental e simulação computacional de um motor flex operando com diferentes misturas de etanol hidratado na gasolina. 2012. Tese de Doutorado. Universidade Federal do Rio de Janeiro.

[12] HEYWOOD, John B. Internal combustion engine fundamentals. New York. 1988.

[13] SILVA, M. H. Carvalho. Orientador: LAGANÁ, A. A. Maria. Modelagem de motores a combustão interna com tecnologia FLEX. Dissertação de mestrado. Escola Politécnica da Universidade de São Paulo. 2018.

[14] MAGGIO, André V. O. Orientador: FILHO, João F. J. Simulação hardware-inthe-loop de um motor de combustão flex. Dissertação de mestrado. Escola Politécnica da Universidade de São Paulo. 2018. No prelo.

[15] NETO, Angelo M. Orientador: LAGANÁ, Armando A. M. Modelagem de um motor com taxa de compressão variável a partir de diferentes taxas fixas e implementação em um hardware-in-the-loop. Dissertação de mestrado. Escola Politécnica da Universidade de São Paulo. 2018. No prelo. 